\title{
Determination of Undissolved Air Content in Oil by Means of a Compression Method
}

\author{
Adam Bureček* - Lumír Hružík - Martin Vašina \\ VŠB - Technical University of Ostrava, Department of Hydromechanics and Hydraulic Equipment, Czech Republic
}

This article describes a combination of experimental and mathematical methods for the determination of undissolved air content in hydraulic oil. The experimental part consists of the determination of the oil bulk modulus, considering the influence of undissolved air by means of a volume compression method in a steel pipe. A multiphase model of an oil/undissolved air mixture is subsequently defined using Matlab SimHydraulics software. The multiphase model permits the volume compression of oil and air bubbles independently of each other. Furthermore, time dependencies of pressures are mathematically simulated during the compression of the multiphase mixture of oil and undissolved air for different concentrations of the latter. The undissolved air content is determined by comparing the mathematically simulated and experimentally measured time dependencies of pressure increases.

Keywords: oil/air mixture, bulk modulus, undissolved air content, hydraulic system

Highlights

- Experimental determination of secant bulk modulus and tangent bulk modulus of oil by means of a compression method.

- $\quad$ Multiphase mathematical model of compressibility of oil/undissolved air mixture.

- Mathematical simulation and measurement of time dependence of pressure during compression of oil/undissolved air mixture in steel pipe.

- Determination of undissolved air content in oil by comparing the mathematical model with the measurement.

- $\quad$ The undissolved air concentrations in the measured hydraulic system were determined in the range of $0.22 \%$ to $0.49 \%$.

\section{O INTRODUCTION}

Basic properties of liquids are described by their density, viscosity and compressibility, which can be expressed by bulk modulus [1] and [2], resistance to deformation, or capacity. Liquid with a content of undissolved air is considered to be a mixture. The bulk modulus of the liquid/undissolved air mixture is significantly influenced by the concentration of undissolved air in the mixture. The mixture bulk modulus generally increases with increasing liquid pressure and decreasing temperature [3]. It is possible to determine the mixture's bulk modulus by different experimental methods, e.g. by acoustic [4] and [5], capacity [6], piezoelectric impedance [7] or volume [8] methods.

Hydraulic oil, which is the most frequently used energy carrier in hydraulic systems, is the investigated liquid in this paper. The air content in hydraulic oil is typically in two states, i.e. in dissolved and undissolved states. In the dissolved (i.e. diffused) state, air in hydraulic oil is in the form of oxygen and nitrogen molecules that are mixed with oil molecules. The contents of other gases in air are negligible in comparison to the oxygen and nitrogen volumes. In the case of the undissolved state, the oxygen and nitrogen molecules are clumped together. For this reason, air bubbles are created. A volume of released and dissolved air in oil is given by Henry's law [9]. Oil with air bubbles creates an oil/undissolved air mixture. The mixture is characterized mainly by a higher compressibility, which corresponds to the relevant bulk modulus (sometimes referred to as effective bulk modulus). Therefore, the effective bulk modulus of an oil/air mixture includes the influence of undissolved air [4], [10] and [11]. The compressibility of the oil/ undissolved air mixture has a negative influence on the static and dynamic properties of hydraulic systems [12]. For this reason, it is necessary to eliminate the air content in this mixture. For a more accurate definition of a mathematical multiphase model of the mixture, it is necessary to define not only the oil bulk modulus, but also the undissolved air content, which is very difficult to measure. There are different methods for the experimental determination of the undissolved air content. It is possible to measure the bubble size distribution in liquid, e.g. by image analysis [13], drift flux analysis [14], as well as by acoustical [15], optical [16] and electro-resistivity [17] methods. However, a given method of the bubble size measurement is generally applicable for a certain bubble size range [18].

The aim of the paper is to describe a specially developed method for the determination of the undissolved air content in hydraulic oil on the basis 
of a comparison of experimental measurements and mathematical modelling.

\section{THEORETICAL BACKGROUNDS}

\subsection{Dissolved Air in 0il}

Air in the dissolved state presents a chemical bond of oxygen and nitrogen molecules to oil molecules. Petroleum oils will generally dissolve $8.5 \% \pm 0.5 \%$ by volume of air at atmospheric pressure and room temperature [19]. For pressures higher than atmospheric levels, absorption follows Henry's law, which is defined as [20]:

$$
H=\frac{C_{a i r}}{C_{\text {oil }}}
$$

where $H$ is the dimensionless Henry's constant, $C_{\text {air }}$ is the solute concentration in air, and $C_{o i l}$ is the solute concentration in oil.

The amount of dissolved air increases with increasing liquid pressure [21]. In the case of a disturbance from the equilibrium state as a consequence of pressure or temperature changes, air molecules are released and air bubbles are generated. For this reason, an oil/air mixture is created, or the air can be further dissolved in oil. This process is timedependent. The time of the air release in oil is much shorter in comparison to the time of its dissolution.

\subsection{Undissolved Air in Oil and Its Influence on Bulk Modulus of Oil/Air Mixture}

Dissolved air in oil is most frequently released to the undissolved state (i.e. to air bubbles) at pressure and temperature changes. Air bubbles can also enter the oil through different leaks. The oil/undissolved air mixture thus obtained has different properties in comparison to oil without air bubbles. It is possible to partly reduce the formation of bubbles at high operating pressures or by means of de-aeration devices, i.e. so-called gas separators. The bulk modulus, which is important in a mathematical model, is a significant property of the oil/undissolved air mixture. It is desirable to achieve high values of the bulk modulus in practice. The bulk modulus of the oil/undissolved air mixture is affected by many factors, e.g. by the pressure, temperature and volume of undissolved air. The amount of undissolved air has the greatest influence on the bulk modulus of the oil/ undissolved air mixture, mainly at low pressures. In this case, the air is much more compressible.
The oil/undissolved air mixture can be defined as a multiphase mixture in mathematical models. The bulk modulus of the multiphase mixture is changed according to pressure and the amount of undissolved air. Then, the bulk modulus $K_{P M}$ of the multiphase oil/ air mixture is given by the equation [2], [22] and [23]:

$$
K_{P M}=K_{O} \cdot \frac{1+\alpha \cdot\left(\frac{p_{a}}{p_{a}+p}\right)^{1 / n}}{1+\alpha \cdot K_{O} \cdot \frac{p_{a}^{1 / n}}{n \cdot\left(p_{a}+p\right)^{(n+1) / n}}},
$$

where $K_{O}$ is the bulk modulus of oil without air content, $\alpha=V_{a} / V_{O}$ is the relative air content in oil at atmospheric pressure, $V_{a}$ is the air volume at atmospheric pressure, $V_{O}$ is the oil volume at atmospheric pressure, $n$ is the isentropic coefficient ( $n=1.4), p$ is the working pressure, and $p_{a}$ is the atmospheric pressure. The above-mentioned equation allows the inclusion of the compression of the oil volume and undissolved air independently of each other.

The oil bulk modulus $K_{O}$ is defined by the following equation [1] and [2]:

$$
K_{O}=\frac{V_{O} \cdot \Delta p}{\Delta V_{O}},
$$

where $\Delta p$ is the pressure difference, and $\Delta V_{O}$ is the difference of oil volume before and after compression.

The bulk modulus of the oil/undissolved air mixture can also be taken into account in a mathematical model in a simplified manner. It is possible to assume a single-phase mixture, in which the compressibility of air bubbles is included in the bulk modulus $K_{M}$ of the oil/undissolved air mixture. In this case, the bulk modulus is defined by a constant for the given working pressure $p$. There is a certain inaccuracy in the mathematical model, especially at lower pressures.

The thermodynamic effect, which is affected by the compression speed, occurs during the compression of the oil/undissolved air mixture. The isothermal effect proceeds at slow compression. In contrast, the isentropic effect is typical for rapid progressive compression. There are four different bulk modulus types of the oil/undissolved air mixture. From one standpoint, there are the secant bulk modulus and the tangent bulk modulus of the mixture [24] and [25] (see Fig. 1). Furthermore, each of these can be further divided into isothermal and isentropic moduli [26]. 


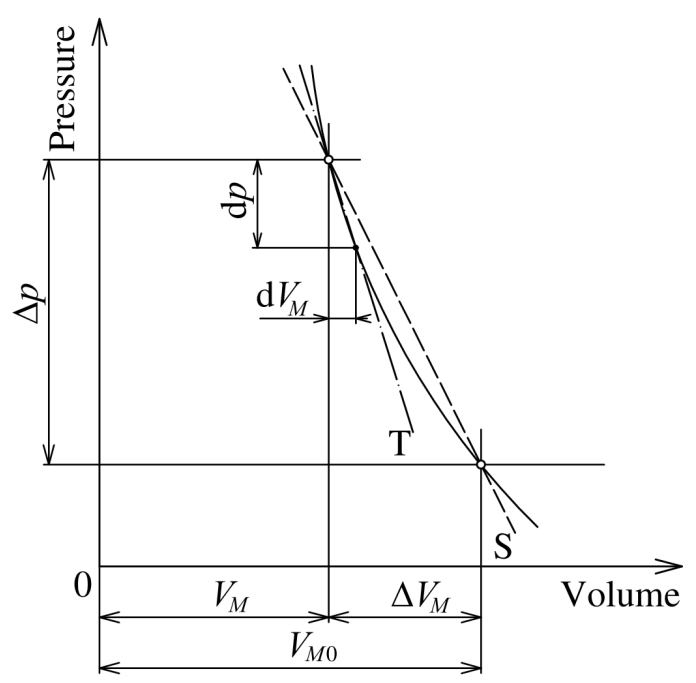

Fig. 1. Determination of secant (S) bulk modulus and tangent (T) bulk modulus of oil/undissolved air mixture

The secant bulk modulus $K_{M, S}$ of the mixture is defined by the formula [10] and [25]:

$$
K_{M, S}=V_{M} \cdot \frac{\Delta p}{\Delta V_{M}}
$$

where $V_{M}$ is the volume of oil/undissolved air mixture, and $\Delta V_{M}$ is the volume difference of an oil/undissolved air mixture before and after compression.

The tangent bulk modulus $K_{M, T}$ of the mixture is expressed by the equation [10] and [25]:

$$
K_{M, T}=V_{M} \cdot \frac{\mathrm{d} p}{\mathrm{~d} V_{M}} .
$$

\section{EXPERIMENTAL MEASUREMENT OF INVESTIGATED MIXTURE}

\subsection{Description of the Experimental Equipment}

The schematic diagram of the experimental equipment is shown in Fig. 2. The equipment consists of the hydraulic pump HP, the check valve $\mathrm{CV}$, the relief valve $R V$, the steel pipe $P$, the seat valve $S V$, the reservoir $\mathrm{R}$, the measuring equipment $\mathrm{M}$ 5050, the measuring point MP, and the pressure sensor PS. The M 5050 measuring equipment allows scanning, display and recording of measuring data from sensors that are used in hydraulics (e.g. from pressure, temperature and flow sensors). The hydraulic pump HP represents a flow source of the hydraulic system. If the seat valve $\mathrm{SV}$ at the pipe end (see Fig. 3) is open, hydraulic oil flows through the pipe $\mathrm{P}$ and the valve into the reservoir R. The seat valve is subsequently closed and,

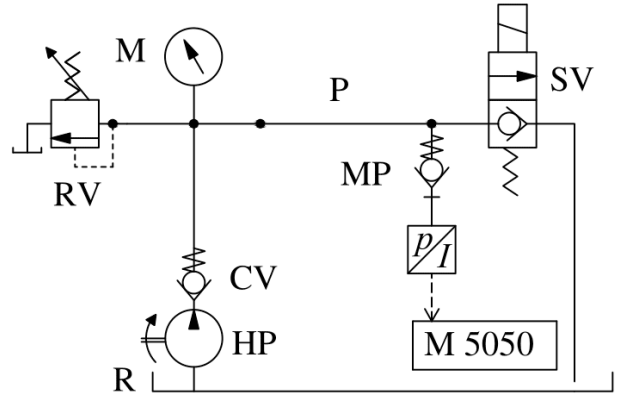

Fig. 2. Schematic diagram of experimental hydraulic circuit for determination of bulk modulus of oil/undissolved air mixture

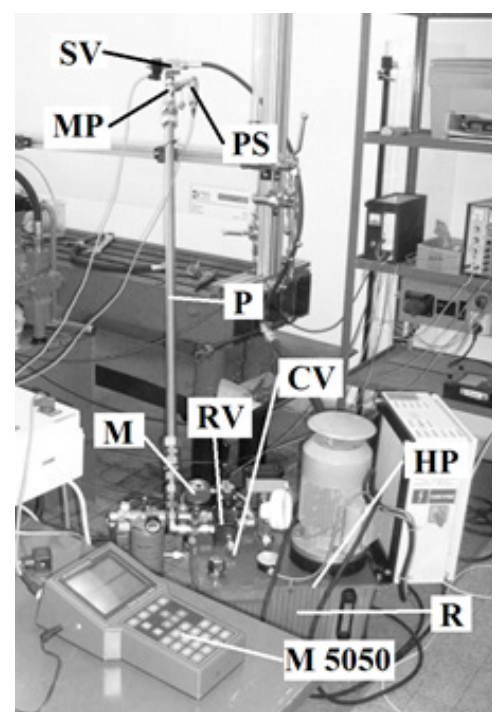

Fig. 3. View of experimental hydraulic circuit for determination of bulk modulus of oil/undissolved air mixture

therefore, the flow through the valve is interrupted. Nevertheless, the pump HP supplies further liquid to the pipe P. Therefore, oil pressure is increased and a mixture of oil and air bubbles is compressed inside the steel pipe $P$. If the pressure of the mixture is increased to the value (i.e. $p=200$ bar), which is adjusted by the relief valve, the relief valve RV is opened and subsequently the mixture of oil and air bubbles flows from the pump HP through the relief valve RV into the reservoir R. At the same time, the oil/undissolved air mixture in the pipe is compressed under the pressure that is adjusted by the relief valve RV. The pressure increase in the pipe was measured depending on the time. The pressure of the oil/undissolved air mixture inside the pipe $\mathrm{P}$ was recorded by the pressure sensor PS and the M 5050 measuring equipment. An example of the time dependence of the pressure $p$ is shown in Fig. 4. The time interval $\Delta t$ of the pressure scanning was set to $1 \mathrm{~ms}$ in this case. Measuring data were 
processed using Hydrowin software. The parameters of the steel pipe $\mathrm{P}$ are as follows: outside diameter $D_{P}=0.03 \mathrm{~m}$, inside diameter $d_{P}=0.022 \mathrm{~m}$, wall thickness $s_{P}=0.004 \mathrm{~m}$, length $l_{P}=1.88 \mathrm{~m}$, Young's modulus of elasticity $E_{P}=2.1 \times 10^{11} \mathrm{~Pa}$ and Poisson ratio $v_{P}=0.3$.

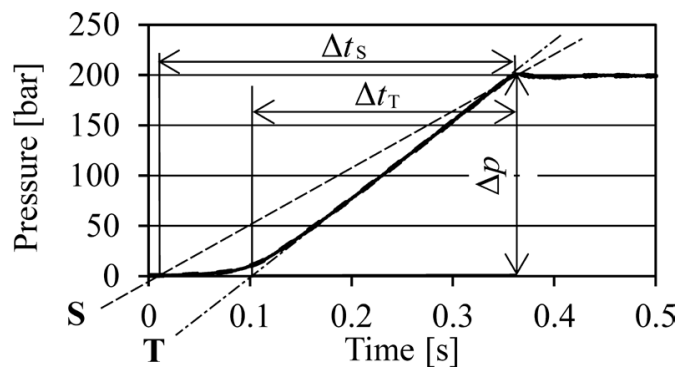

Fig. 4. Measurement record of time dependence of pressure during mixture compression in steel pipe

The oil density $\rho=859 \mathrm{kgm}^{-3}$ was measured using a Mohr balance. The kinematic viscosity $v=1.02 \times 10^{-4}$ $\mathrm{m}^{2} \mathrm{~s}^{-1}$ of the investigated hydraulic oil was determined using a Brookfield DV-II+ Pro rotational viscometer. The above-mentioned quantities were determined for the oil temperature $t_{O}=25^{\circ} \mathrm{C}$.

\subsection{Experimental Determination of Bulk Modulus of Oil/ Undissolved Air Mixture}

The method of determination of the secant bulk modulus and the tangent bulk modulus of the oil/ undissolved air mixture is described in this chapter.

The time dependence of the pressure $p$ in the pipe $\mathrm{P}$ is shown in Fig. 4. The maximum pressure $p=200$ bar corresponds to the pressure that is adjusted by the relief valve RV. Also shown on this figure are the secant " $\mathrm{S}$ " and the tangent " $\mathrm{T}$ " for the determination of the secant bulk modulus $K_{M, S}$ and the tangent bulk modulus $K_{M, T}$ of the oil/undissolved air mixture for the pressure gradient $\Delta p=200$ bar. Appropriate secants " $\mathrm{S}$ " or tangents " $\mathrm{T}$ " were determined for obtaining the secant bulk modulus and the tangent bulk modulus of the mixture at different pressure gradients $\Delta p$ (see Fig. 6). It is evident (see Fig. 4) that the secant slope is influenced by the nonlinear dependence of the pressure $p$ depending on the time $t$ at the beginning of compression of the mixture in the pipe $\mathrm{P}$. The nonlinearity is caused by the compression of air bubbles present in oil. The tangents " $\mathrm{T}$ " and the corresponding values of the tangent bulk modulus $K_{M, T}$ were determined only for the pressures occuring when the effect of oil compression is included and the effect of compression of air bubbles is negligible.
The time intervals $\Delta t$ depending on the pressure changes $\Delta p$ were subtracted from the experimentally measured record (see Fig. 4). The appropriate time interval $\Delta t_{T}$ was subtracted for the determination of the tangent bulk modulus. Similarly, the appropriate time interval $\Delta t_{S}$ was subtracted for the determination of the secant bulk modulus. The volume increase $\Delta V_{M}$ [5] and [23] of the mixture in the pipe $\mathrm{P}$ due to the pressure change $\Delta p$ is given by equation:

$$
\Delta V_{M}=\sum_{i=1}^{n} Q_{i} \cdot \Delta t_{i}
$$

The given pressure change $\Delta p$ (see Fig. 4) was divided into equidistant sub-intervals $\left(\Delta p_{i}=2.5\right.$ bar $)$ with the corresponding time sub-intervals $\Delta t_{i}$. The sub-flows $Q_{i}$ were subsequently determined from the measured flow-pressure characteristic of the pump HP (see Fig. 5). The average flow rate $Q_{i}$ was subtracted from the flow-pressure characteristic of the pump for each pressure sub-interval $\Delta p_{i}$.

The flow-pressure characteristic depends on the temperature of the mixture. Therefore, the characteristic was experimentally measured for the working oil temperature $t_{O}=25^{\circ} \mathrm{C}$. The influence of the change of air content in oil in the reservoir on the flow-pressure characteristic was negligible.

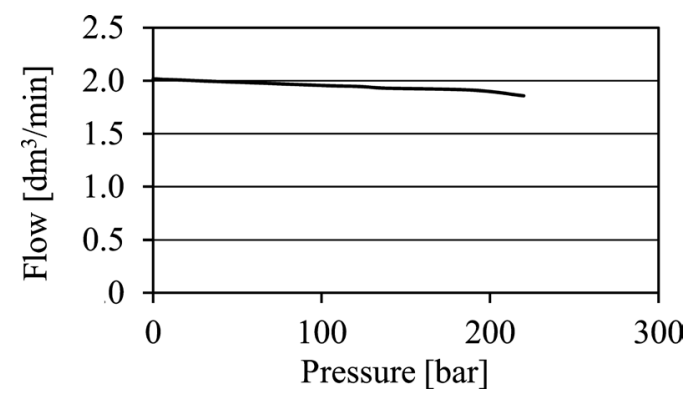

Fig. 5. Flow-pressure characteristic of the hydraulic pump HP, $t_{0}=25^{\circ} \mathrm{C}$

The bulk modulus $K_{M}$ of the oil/undissolved air mixture is subsequently defined by the formula [27]:

$$
K_{M}=\frac{1}{\frac{\Delta V_{M}}{V_{M} \cdot \Delta p}-\frac{d_{p}}{E_{p} \cdot s_{p}}} .
$$

The measured dependencies of the secant bulk modulus $K_{M, S}$ and the tangent bulk modulus $K_{M, T}$ of the oil/undissolved air mixture on the pressure gradient $\Delta p$ are shown in Fig. 6. It is evident that the secant bulk modulus of the oil/undissolved air mixture is increasing with increases of the pressure gradient $\Delta p$. The secant bulk modulus is significantly influenced by the compression of air bubbles in the 
nonlinear area (see Fig. 4). The tangent bulk modulus $K_{M, T}$ is practically constant and represents oil without influence of air bubbles. It comes very close to the oil bulk modulus $K_{O}$ (see Eq. 3). The measured values of the secant bulk modulus $K_{M, S}$ and the tangent bulk modulus $K_{M, T}$ of the oil/undissolved air mixture are shown in Tab. 1. These values were obtained from Fig. 6 for the pressure gradient $\Delta p=200$ bar.

Table 1. Measured values of the secant bulk modulus $K_{M, S}$ and the tangent bulk modulus $K_{M, T}$ of oil/undissolved air mixture for the pressure gradient $\Delta p=200 \mathrm{bar}$

\begin{tabular}{cc}
\hline$K_{M, S}\left(\times 10^{9} \mathrm{~Pa}\right)$ & $K_{M, T}\left(\times 10^{9} \mathrm{~Pa}\right)$ \\
\hline 1.64 & 1.78 \\
\hline
\end{tabular}

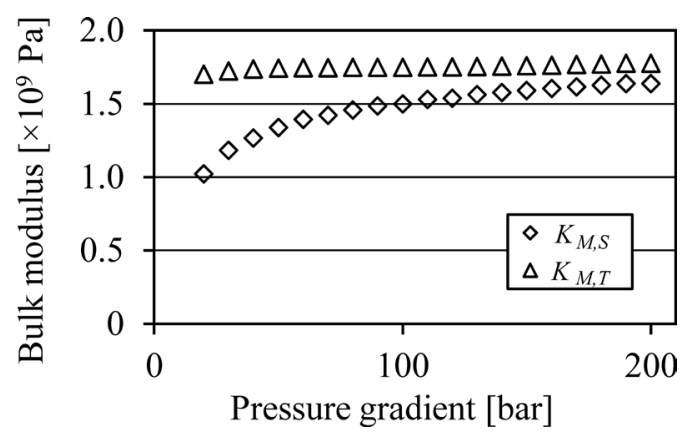

Fig. 6. Dependence of the secant bulk modulus $K_{M, S}$ and the tangent bulk modulus $K_{M, T}$ of oil/undissolved air mixture on the pressure gradient $\Delta p$

\subsection{Experimental Measurement of Time Dependence of Pressure for Differently Aerated Systems}

The time dependence of the mixture pressure in the steel pipe was experimentally measured during compression of the investigated mixture. The measurements were repeatedly performed for different degrees of oil aeration. De-aeration was performed via multiple compressions of the oil/undissolved air mixture in the pipe up to the pressure $p=200 \mathrm{bar}$. The time dependence of the mixture pressure was measured for each compression. The air concentration decreases with successive compressions in the pipe P (see Fig. 7) due to successive de-aeration of the system. Dead volumes in the system (e.g. in connections, screw joints and valves) are successively de-aerated at individual compressions of the system. A part of the air bubbles is released from dead volumes during each compression. These bubbles are subsequently drained away from the working volume. It is evident (see Fig. 8) that the pressure increase is faster after each compression. The compression speed is given by the

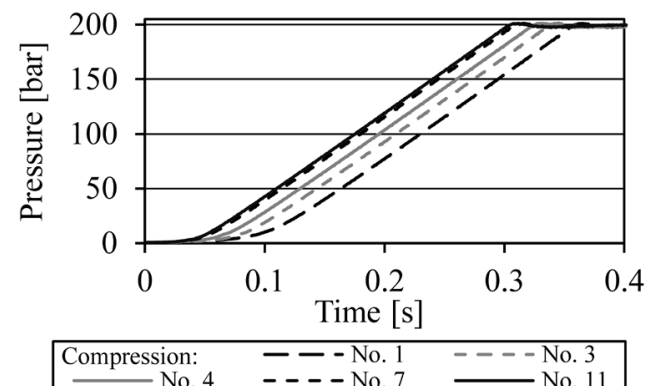

Fig. 7. Measured time dependencies of mixture pressure for differently aerated system

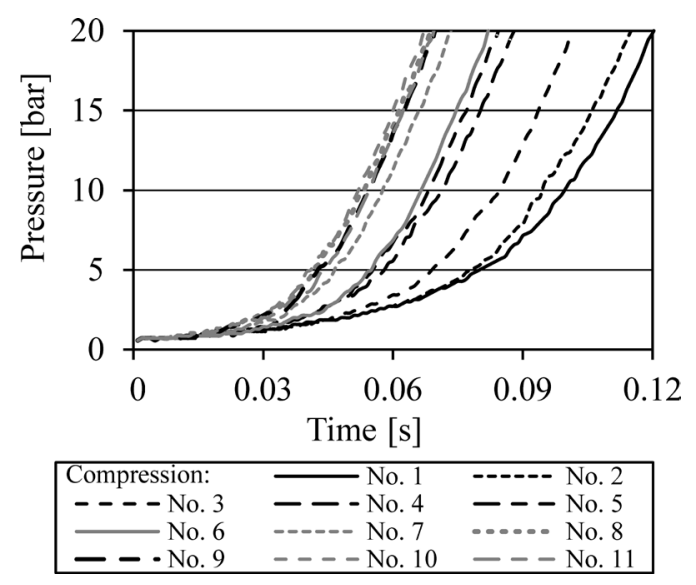

Fig. 8. Detail of measured time dependencies of the mixture pressure for differently aerated system

flow size from the pump, the constant volume inside the pipe, Young's modulus of elasticity of the steel pipe and the bulk modulus of the mixture of oil and air bubbles. The time dependencies of the pressure at the beginning of compression are nonlinear, which is caused by the compression of air bubbles. It is also evident that the time dependencies of the pressure are practically identical during the last three compression processes (i.e. for compressions No. 9, 10 and 11). It can be concluded that it was practically impossible to decrease the air content in the oil/undissolved air mixture during further compression processes. The linear area is characterized by the same inclination angle of the pressure dependencies (see Fig. 7). For this reason, the undissolved air is markedly compressed.

\section{MATHEMATICAL MODEL}

The mathematical model (see Fig. 9) of the experimental equipment was created using Matlab SimHydraulics software [22]. The constant flow pump 
HP represents a source of pressure energy. Oil flows through the check valve $\mathrm{CV}$, the steel pipe $\mathrm{P}$, the seat valve SV into the reservoir R. In the case of closing of the seat valve SV, the oil pressure in the pipe $\mathrm{P}$ increases up to the pressure value, which is adjusted by the relief valve RV. The circuit also consists of the block for valve control (i.e. Control of SV), the block PS for pressure measurement, the solver block (i.e. Solver) and the block for definition of the oil/ undissolved air mixture (i.e. Oil-Air) [28].

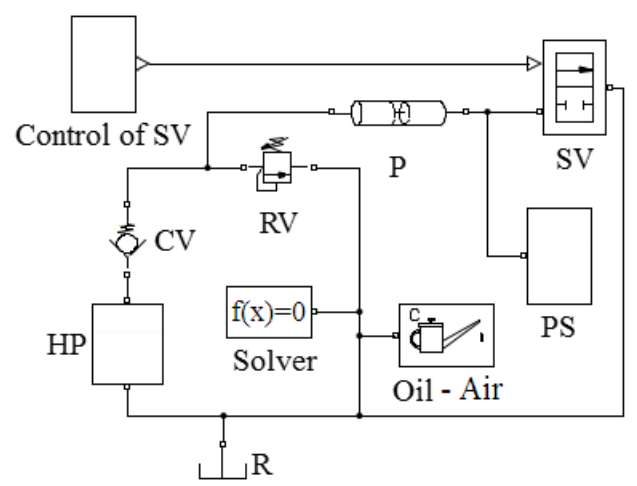

Fig. 9. Mathematical model of experimental equipment

The steel pipe P (see Fig. 9) is simulated as a segmented pipe with circular cross-section, which is divided by longitudinal cuts on set of same serially arranged parts, i.e. concentric parameters. Each part of the pipe consists of the Resistive Tube (i.e. resistance to motion), the Fluid Inertia (i.e. resistance to acceleration) and the Constant Volume Hydraulic Chamber (i.e. resistance to deformation). In the case of one segment, a symmetric T-part is assumed. Any other segment is regarded as an L-part. The parameters of the steel pipe are presented in Chapter 2.1. The pipe wall was defined as elastic, and its elasticity is expressed by the pressure-diameter coefficient $K_{P}$ [22]:

$$
K_{P}=\frac{d_{p}}{E_{p}} \cdot\left(\frac{D_{p}^{2}+d_{p}^{2}}{D_{p}^{2}-d_{p}^{2}}+v_{p}\right) .
$$

The single-phase mathematical model of the oil/ undissolved air mixture is defined by the density $\rho$, the kinematic viscosity $v$ and the bulk modulus $K_{M}$ of this mixture in Matlab SimHydraulics (i.e. in the block Oil-Air). In case of the multiphase mathematical model of the oil/undissolved air mixture, it is also necessary to enter the amount of the undissolved air content $\alpha$.

\section{RESULTS AND DISCUSSION}

\subsection{Simulation of the Influence of the Bulk Modulus of an Oil/Undissolved Air Mixture on the Time Dependence of Pressure - Single-Phase Model}

The influence of the bulk modulus $K_{M}$ of the singlephase oil/undissolved air mixture on time dependencies of the pressure $p$ was mathematically simulated during closing of the seat valve SV at the end of the pipe $\mathrm{P}$ (see Fig. 9). The bulk modulus of the investigated mixture was described in this mathematical model by a constant that already includes the compressibility of air bubbles. The pressure increases depending on time for different values of the bulk modulus of the single-phase mixture are shown in Fig. 10. The time dependencies of the mixture pressure are linear with different angles of inclination. It can be concluded that the angle of inclination of the pressure dependence increases with increases of the bulk modulus, and the maximum pressure is achieved in a shorter time.

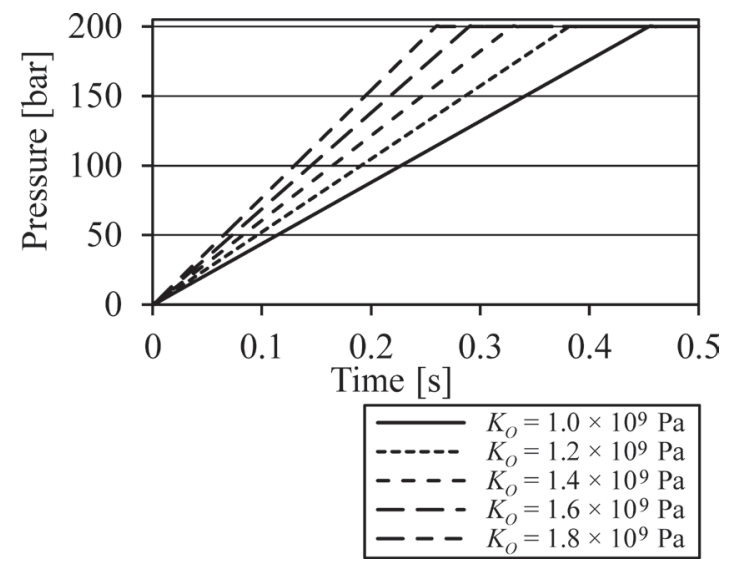

Fig. 10. Simulation of influence of bulk modulus of single-phase oil/undissolved air mixture on time dependencies of pressure

The experimental and simulated time dependencies of the pressure increases are compared in Fig. 11. The experimentally obtained values of the secant bulk modulus and the tangent bulk modulus of the oil/undissolved air mixture at the pressure $p=200$ bar were applied to the simulation in the singlephase model. Furthermore, this model was specified without the undissolved air content (i.e. with $\alpha=0$ ). It corresponds to the single-phase mixture with the constant bulk modulus.

It is evident that the simulated time dependence of the pressure with the tangent bulk modulus $K_{M, T}$ of the oil/undissolved air mixture and the experimentally measured pressure dependence have the same angle 
of inclination in the linear area (see Fig. 11). As previously mentioned, air bubbles are markedly compressed in this area. For this reason, the tangent bulk modulus of the mixture is approaching the oil bulk modulus $K_{O}$. Therefore, in the case of the multiphase oil/undissolved air mixture (see Eq. 2), the tangent bulk modulus $K_{M, T}$ of the oil/undissolved air mixture is used as the oil bulk modulus $K_{O}$ in mathematical simulations. The undissolved air content $\alpha$ is the last unknown quantity in the application of the multiphase model. The method for determining this parameter is described in the following chapter.

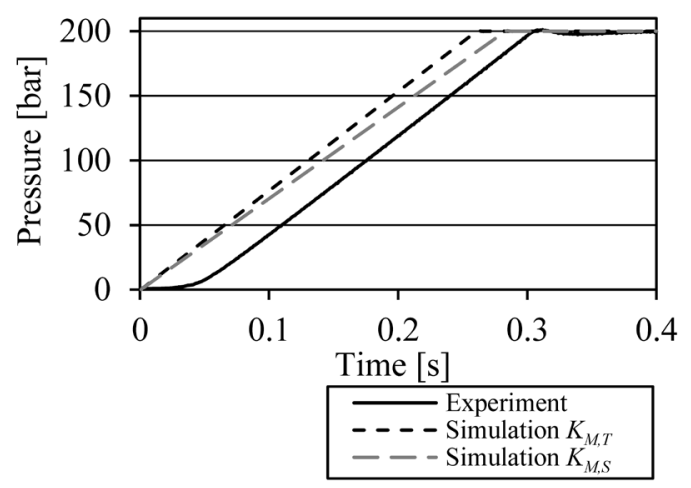

Fig. 11. Comparison of mathematical simulations for experimentally determined secant bulk modulus $K_{M, S}$ and tangent bulk modulus $K_{M, T}$ of oil/undissolved air mixture with experimental measurement

\subsection{Simulation of the Influence of Undissolved Air on the Time Dependence of Pressure - Consideration of a Multiphase Model}

The bulk modulus of the multiphase oil/undissolved air mixture (see Eq. 2) was taken into account in the mathematical multiphase model. In this case, the experimentally determined tangent bulk modulus $K_{M, T}$ (see Fig. 6) was used as the oil bulk modulus $K_{O}$, i.e. without influence of air bubbles. The time dependencies of the pressure were subsequently simulated for different contents $\alpha$ of undissolved air in the mixture. The influence of the air content on the simulated pressure dependencies is evident from Fig. 12. Higher air contents result in higher nonlinearities in the area of low pressures. Furthermore, the experimentally measured time dependencies of the pressure for aerated and partially de-aerated oil mixtures are compared in Fig. 12.

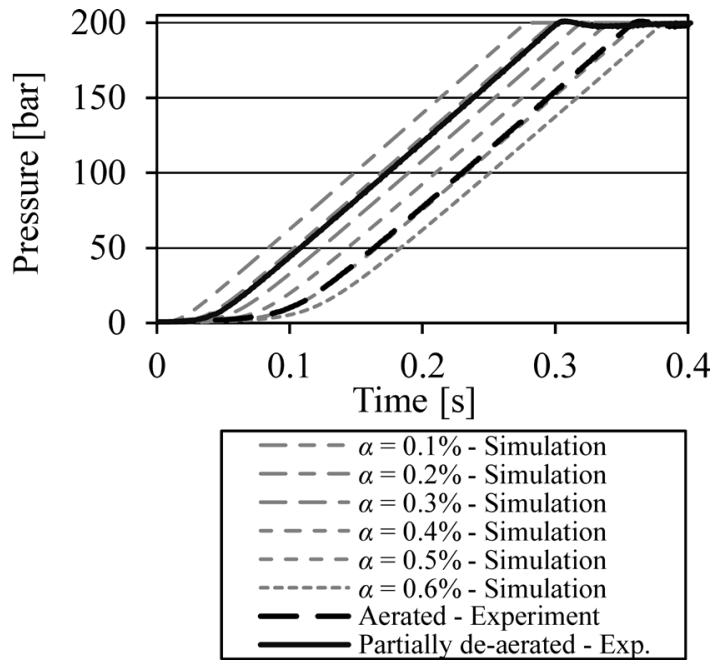

Fig. 12. Comparison of experimental measurements and simulations of influence of undissolved air content on time dependencies of pressure

It is possible to determine the undissolved air content in oil with a comparison of the measured and simulated pressure dependencies (see Fig. 12). In this case, the undissolved air content $\alpha=0.49 \%$ was determined for the aerated oil (i.e. for the compression No. 1, see Fig. 7). Similarly, the undissolved air content $\alpha=0.22 \%$ was obtained for the partially deaerated oil (i.e. for the compression No. 11, see Fig. 7). The multiphase mathematical model captures very well the influence of the compressibility of air bubbles in the area of low pressures. This mathematical model was also used in the following application: the volume of oil/undissolved air mixture, which expanded from the pipe during a rapid decrease of working pressure to atmospheric pressure, was experimentally measured. The similar volume values were determined using the mathematical model. The measured time dependence of the pressure decrease also corresponded to the mathematical simulation [29].

\section{CONCLUSION}

The purpose of this paper was to determine the concentrations of undissolved air in an oil/ undissolved air mixture. It was necessary to obtain the properties of the mixture in order to determinate the concentrations of the undissolved air for the definition of a mathematical model. For this reason, the values of the secant bulk modulus and the tangent bulk modulus of the oil/undissolved air mixture were experimentally obtained using a volume compression method. Time dependencies of the mixture 
pressure were subsequently created using Matlab SimHydraulics software and compared with the experimental measurements. The measured values of the secant bulk modulus and the tangent bulk modulus of the mixture were applied to the single-phase model. The simulated pressure dependence using the mixture tangent bulk modulus and the experimental pressure dependence have the same angle of inclination in the linear area. There is a negligible influence of bubble compression in this area. Therefore, the mixture tangent bulk modulus is used for the specification of hydraulic oil in the mathematical model. The tangent bulk modulus is almost constant and represents oil without the influence of air bubbles. It corresponds to the oil bulk modulus.

Time dependencies of the mixture pressure were subsequently simulated in the multiphase model for different contents of undissolved air in the mixture. The influence of undissolved air on the pressure increase was found on the basis of the experimental measurements for the differently aerated system. The undissolved air content was determined by a comparison of the simulated and experimentally measured pressure dependencies. The linear area of the pressure dependencies is influenced by the oil bulk modulus. The nonlinear area of these dependencies is mainly affected by the undissolved air content. The mathematical description of the bulk modulus of the oil/undissolved air mixture includes the effect of the compression of air bubbles in areas of low pressures. This corresponds well to the physical experiment.

\section{ACKNOWLEDGEMENTS}

This paper has been written within the framework of the project Opportunity for young researchers, reg. no. CZ.1.07/2.3.00/30.0016, supported by Operational Programme Education for Competitiveness and cofinanced by the European Social Fund and the state budget of the Czech Republic.

The work presented in this paper was also supported by grant SGS "Zkoumání dynamiky hydraulického vedení” SP2014/208.

\section{REFERENCES}

[1] Bullock, G.N., Crawford, A.R., Hewson, P.J., Walkden, M.J.A., Bird, P.A.D. (2001). The influence of air and scale on wave impact pressures. Coastal Engineering, vol. 42, no. 4, p. 291312, D0l:10.1016/S0378-3839(00)00065-X.

[2] Petrović, R., Živković, M., Rong, W. Z., Rakić, D., Slavković, R. (2014). Influence of Air Content Entrained in Fluid of a Vane
Pump with Double Effect Operating Parameters. Tehnički vjesnik - Technical Gazette, vol. 21, no. 2, p. 401-407.

[3] Wilson, D.R., Marshall, W.A., Dolle, R.E., Bezing, R.J. (1967). Physical, Chemical, and Mechanical Characteristics of a Polyphenyl Ether. I\&EC Product Research and Development, vol. 6, no. 2, p. 81-88, Dol: 10.1021/i360022a001.

[4] Van de Ven, J.D. (2013). On Fluid Compressibility in SwitchMode Hydraulic Circuits - Part II: Experimental Results. Journal of Dynamic Systems Measurement and Control-Transactions of the ASME, vol. 135, no. 2, 021013, D0I:10.1115/1.4023062.

[5] Karadžić, U., Bulatović, V., Bergant, A. (2014). Valve-Induced Water Hammer and Column Separation in a Pipeline Apparatus. Strojniški vestnik - Journal of Mechanical Engineering, vol. 60 , no. 11, p. 742-754, D0I:10.5545/svjme.2014.1882.

[6] Kiselev, V.D., Bolotov, A.V., Satonin, A., Shakirova, I., Kashaeva, H.A., Konovalov, A.I. (2008). Compressibility of Liquids. Rule of Noncrossing V-P Curvatures. Journal of Physical Chemistry B, vol. 112, no. 21, p. 6674-6682, Dol: 10.1021/.jp800513d.

[7] Kim, G., Wang, K. (2009). On-line Estimation of Effective Bulk Modulus in Fluid Power Systems Using Piezoelectric Transducer Impedance. Journal of Intelligent Material Systems and Structures, vol. 20, no. 17, p. 2101-2106, D0I:10.1177/1045389X09345558.

[8] Bureček, A. (2013). Fluid Structure Interaction in Case of NonStationary Flow. PhD thesis, VŠB - Technical University in Ostrava, Czech Republic.

[9] Gorgenyi, M., Dewulf, J., Van Langenhove, H. (2002). Temperature dependence of Henry's law constant in an extended temperature range. Chemosphere, vol. 48, no. 7, p. 757-762, DOI:10.1016/S0045-6535(02)00131-5.

[10] Van de Ven, J.D. (2013). On Fluid Compressibility in SwitchMode Hydraulic Circuits - Part I: Modeling and Analysis. Journal of Dynamic Systems Measurement and ControlTransactions of the ASME, vol. 135, no. 2, 021013 , DOl:10.1115/1.4023062.

[11] Gholizadeh, H., Burton, R., Schoenau, G. (2012). Fluid Bulk Modulus: Comparison of Low Pressure Models. International Journal of Fluid Power, vol. 13, no. 1, p. 7-16, Dol:10.1080/14 399776.2012.10781042.

[12] Datta, B.N., Murty, A.S.R., Sinha, G.L. (1986). Effect of entrained air on dynamic characteristics of hydraulic servosystem with asymmetric linear motor. Meccanica, vol. 21, no. 1, p. 51-57, D0l:10.1007/BF01556317.

[13] Grau, R.A., Heiskanen, K. (2002). Visual technique for measuring bubble size in flotation machines. Minerals Engineering, vol. 15, no. 7, p. 507-513, D0l:10.1016/S08926875(02)00074-2.

[14] Dobby, G.S., Yianatos, J.B., Finch, J.A. (1988). Estimation of Bubble Diameter in Flotation Columns from Drift Flux Analysis. Canadian Metallurgical Quarterly, vol. 27, no. 2, p. 85-90, DOI:10.1179/000844388795576493.

[15] Wu, X.J., Chahine, G.L. (2010). Development of an acoustic instrument for bubble size distribution measurement. Journal of Hydrodynamics, vol. 22, no. 5, p. 325-331, Dol:10.1016/ S1001-6058(09)60214-6.

[16] Saberi, S., Shakourzadeh, K., Bastoul, D., et al. (1995). Bubble-Size and Velocity-Measurement in Gas-Liquid Systems 
- Application of Fiber Optic Technique to Pilot-Plant Scale. Canadian Journal of Chemical Engineering, vol. 73, no. 2, p. 253-257, DOI:10.1002/cjce.5450730213.

[17] Kocamustafaogullari, G., Huang, W.D., Razi, J. (1994). Measurement and Modeling of Average Void Fraction, BubbleSize and Interfacial Area. Nuclear Engineering and Design, vol. 148, no. 2-3, p. 437-453, D0l:10.1016/0029-5493(94)901244.

[18] Rodrigues, R.T., Rubio, J. (2003). New Basis for Measuring the Size Distribution of Bubbles. Minerals Engineering, vol. 16, no. 8, p. 757-765, DOl:10.1016/S0892-6875(03)00181-X.

[19] Wahi, M.K. (1976). Oil compressibility and polytropic air compression analysis for oleopneumatic shock struts. Journal of Aircraft, vol. 13, no. 7, p. 527-530, D0l:10.2514/3.44540.

[20] Shimotori, T., Arnold, W.A. (2003). Measurement and estimation of Henry's law constants of chlorinated ethylenes in aqueous surfactant solutions. Journal of Chemical and Engineering Data, vol. 48, no. 2, p. 253-261, Dol:10.1021/ je025553z.

[21] Blanchard, L.A., Gu, Z.Y., Brennecke, J.F. (2001). Highpressure phase behavior of ionic liquid/CO2 systems. Journal of Physical Chemistry, vol. 105, no. 12, p. 2437-2444, D0I:10.1021/.jp003309d.

[22] The MathWorks (2007). Matlab Simulink User's Guide, SimHydraulics User's Guide, USA.

[23] Xu, M., Ni, J., Chen, G. (2014). Dynamic Simulation of VariableSpeed Valve-Controlled-Motor Drive System with a Power-
Assisted Device. Strojniški vestnik - Journal of Mechanical Engineering, vol. 60, no. 9, p. 581-591, Dol:10.5545/svjme.2013.1532.

[24] Gholizadeh, H., Burton, R., Schoenau, G. (2011). Fluid Bulk Modulus: A Literature Survey. International Journal of Fluid Power, vol. 12, no. 3, p. 5-15, Dol:10.1080/14399776.2011. 10781033.

[25] Hayward, A.T.J. (1967). Compressibility equations for liquids: a comparative study. British Journal of Applied Physics, vol. 18, no. 7, p. 965-977, D0l:10.1088/0508-3443/18/7/312.

[26] Boehman, A.L., Morris, D., Szybist, J. (2004). The Impact of the Bulk Modulus of Diesel Fuels on Fuel Injection Timing. Energy \& Fuels, vol. 18, no. 6, p. 1877-1882, D0l: 10.1021/ ef049880j.

[27] Hružík, L., Vašina, M. (2009). Nondestructive Testing for Experimental Determination of Elastic Modulus of Rubber Hoses. Acta Hydraulica et Pneumatica, vol. 1, no. 7, p. 12-16.

[28] Lei, L., Desheng, Z., Jiyun, Z. (2014). Design and Research for the Water Low-pressure Large-flow Pilot-operated Solenoid Valve. Strojniški vestnik - Journal of Mechanical Engineering, vol. 60, no. 10, p. 665-674, D0l:10.5545/sv-jme.2014.1688.

[29] Hružík, L., Bureček, A., Vašina, M. (2013). Measurement and Numerical Simulation of Hydraulic Hose Expansion. Proceedings of $5^{\text {th }}$ International Scientific and Expert Conference of the International TEAM Society, vol. 5, no. 1, p. 222-225. 